\title{
THE REMOVAL OF IRON FROM HARD PULVERISED KAOLIN BY DRY HIGH-GRADIENT MAGNETIC SEPARATION*
}

\author{
YU KANG CHUN \\ Bureau for Geology and Mineral Resources of Zhejiang Province, Hangzhou, \\ Zhejiang Province 310007, China
}

\begin{abstract}
Deposits of hard kaolin are abundant in China, with kaolin content in the ore exceeding $95 \%$. It is, however, rather difficult to remove iron from the ore. It was demonstrated that wet high-gradient magnetic separation is very efficient in removing the iron compounds from kaolin. For hard kaolin, however, dry high-gradient magnetic separation (HGMS) may be more suitable. To this end, we have developed a new type of dry HGMS device for laboratory use. The separation performance of the device was tested as a function of the iron concentration in the ore, gas velocity, magnetic induction and the intensity of the vibrating current. The following results were achieved: for sample no. 1 of hard kaolin, the content of $\mathrm{Fe}_{2} \mathrm{O}_{3}$ was reduced from about $2.20 \%$ to $.082 \%$, with the yield of the concentrate of $86.5 \%$. For no. 2 sample of hard kaolin, the content of $\mathrm{Fe}_{2} \mathrm{O}_{3}$ was reduced from about $0.60 \%$ to $0.48 \%$, with the yield of the concentrate $83.15 \%$. The removal of the iron oxide from hard kaolin by dry HGMS proved to be feasible. Industrial-scale dry HGMS device was built and installed at a mine at the end of 1993 .
\end{abstract}

\section{INTRODUCTION}

Using a filamentary matrix, high-gradient magnetic separator (HGMS) can produce strong magnetic force and remove effectively weakly magnetic particles. HGMS can be either wet or dry, depending on the medium that carries the particles. Wet HGMS is efficient in removing iron compounds from kaolin [1]. For hard pulverised kaolin, however, wet HGMS has several disadvantages: the need for water to slurry the kaolin, and the need for dewatering and drying the concentrate. Dry HGMS would enable to eliminate the above mentioned disadvantages which would result in considerable economical effect. 
The only reports on dry HGMS concerned the removal of sulphur from coal $[2,3$, 4] and of iron from ash in power plants [5]. Since the application of dry HGMS to kaolin purification has not been reported we developed a laboratory-scale dry HGMS separator and conducted tests on hard pulverised kaolin.

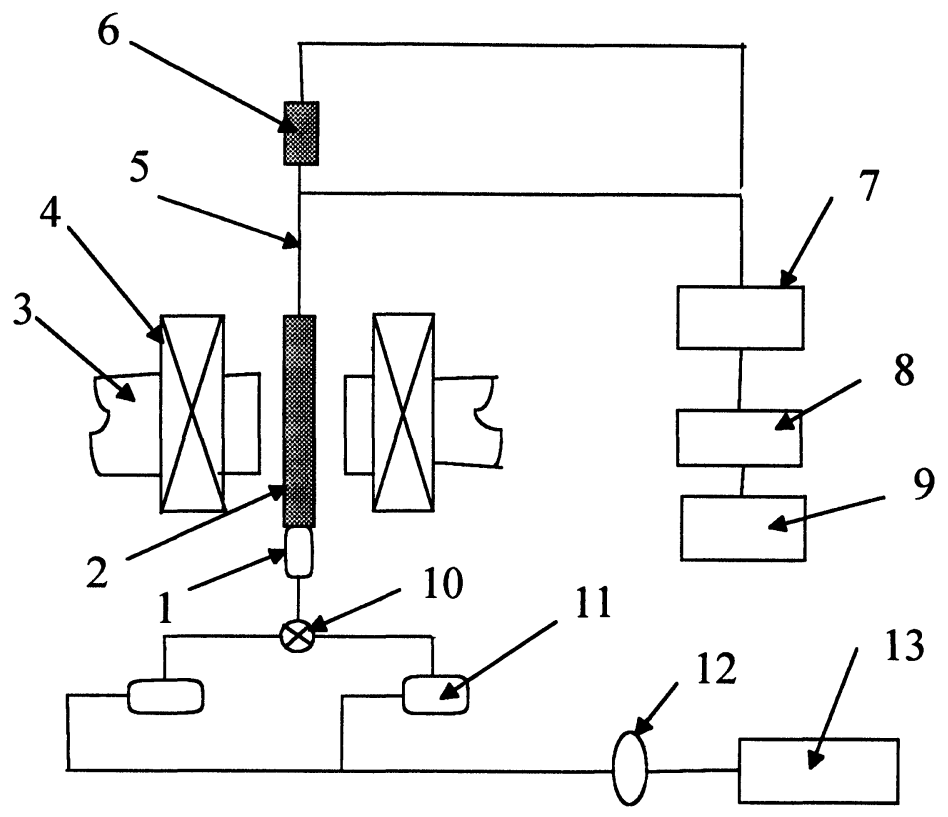

Fig. 1 Schematic diagram of the laboratory dry vibrating HGMS apparatus. 1-vibrating coil, 2-separation chamber, 3-iron core, 4-magnetising coil, 5-gas expansion device, 6-feeder, 7-dryer, 8-liquid-air separator, 9-air compressor, 10-triple valve, 11-powder collecting device, 12-flowmeter, 13-vacuum air pump. 


\section{EXPERIMENTAL}

\section{Experimental Apparatus}

The laboratory-scale dry HGMS separator is shown in Fig. 1. It operates in the following manner:

(a) Dry compressed gas forces the kaolin powder out of the expansion device with a high velocity so that the powder is dispersed before entering the separation chamber.

(b) The coils encircling both ends of the separation chamber are placed in the leakage magnetic field of the pole tips. When the a.c. current is switched on an alternating magnetic moment acts on the coils to make the separation chamber vibrate. This makes also the matrix vibrate. The mechanical clogging is thus reduced and the efficiency of separation improved.

\section{Sample no. 1 of Hard Kaolin}

The concentration of of $\mathrm{Fe}_{2} \mathrm{O}_{3}$ in sample no. 1 is approximately $2.2 \%$. The key variables affecting the experimental results are: the gas velocity, magnetic induction and intensity of the vibrating current. The following parameters were kept constant: the filling factor of the matrix: $11.5 \%$, feed: $7 \mathrm{~g}$, feed time: 4 minutes.

Figure 2 shows the influence of gas velocity on the results of separation (magnetic induction: $1.5 \mathrm{~T}$, vibrating current: $3.0 \mathrm{~A}$ ). The iron removal decreases, the yield of the concentrate (the non-magnetic fraction) increases, and the iron content in the concentrate increases with the increase of gas velocity. When the gas velocity is smaller than $2.2 \mathrm{~m} / \mathrm{s}$, the kaolin powder deposits in horizontal pipes. For this reason is the gas velocity taken as $2.20 \mathrm{~m} / \mathrm{s}$ which results in the reduction of the concentration of iron oxide from $2.2 \%$ to $0.82 \%$, with the yield of the concentrate of $80.15 \%$.

Vibration of the separation chamber and of the matrix is related to the magnetic induction and the vibrating current. Experimental points and experimental results are summarised in Table I. By comparing the experiments 1 and 2, 3 and 4 and 5 
and 6 in Table $I$, it can be seen that at the same magnetic induction the concentrate yield is directly proportional to the vibrating current while the iron reduction and iron content in the concentrate are slightly lower.

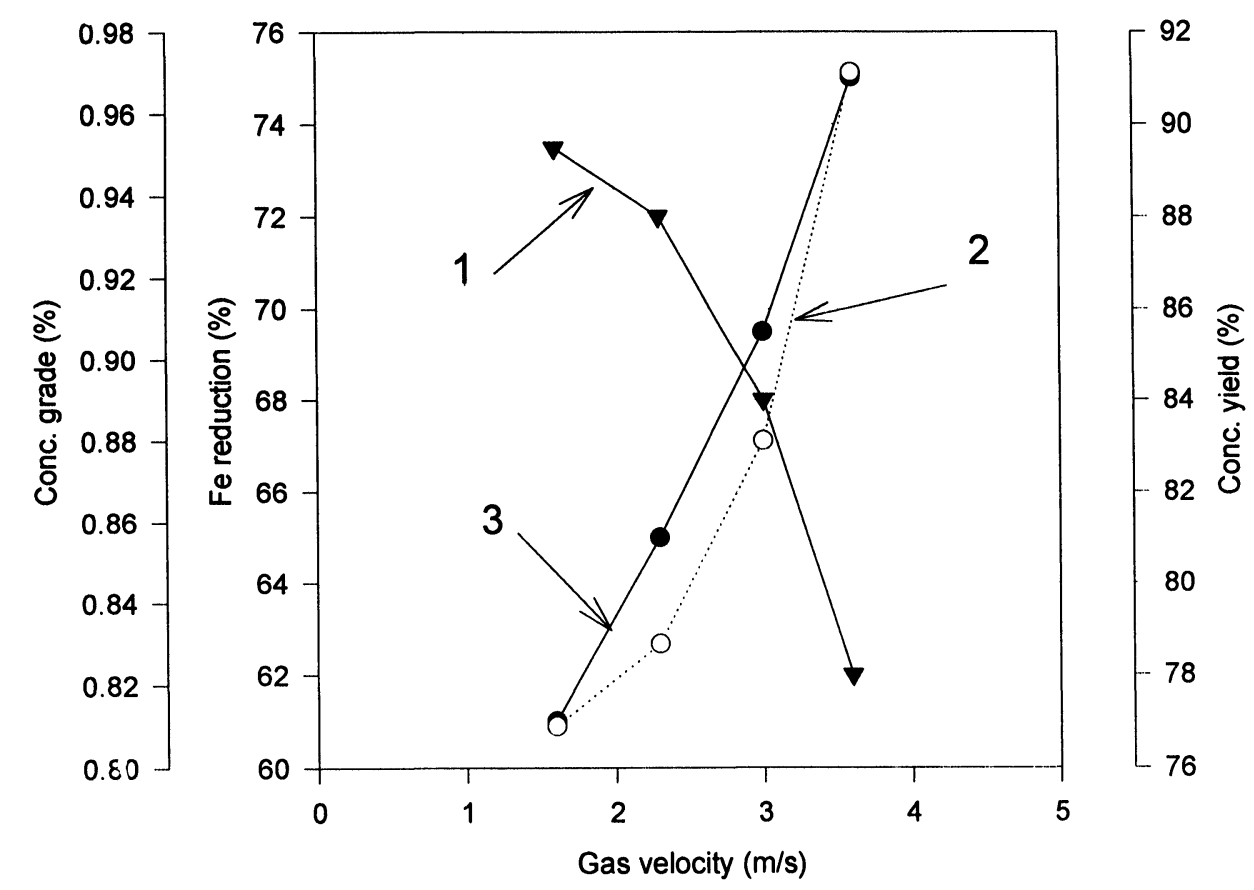

Fig. 2 The yield (3) and the grade of the concentrate (2), and the reduction of iron (1), as a function of gas velocity.

Comparing the experimental points $1,3,5$ and 2,4,6, it can be seen that the yield of the concentrate increases with increasing magnetic induction while the iron reduction and the iron content hardly change, except for test no. 1. Taking into account the energy consumption, experiment no. 4 was adopted, namely magnetic induction $1.0 \mathrm{~T}$ and the vibrating current of $3.5 \mathrm{~A}$.

Based on the above experiments, the optimum conditions were selected from a group of parallel experiments. These conditions are as follows: magnetic induction: $1.0 \mathrm{~T}$, gas velocity: $2.2 \mathrm{~m} / \mathrm{s}$, filling factor of the matrix: $11.5 \%$, vibrating current: 
3.5 A, feed: $7 \mathrm{~g}$ and feed time: 4 minutes. The results thus obtained are summarised in Table II.

Table I The arrangement of experimental points and the experimental results.

\begin{tabular}{|c|c|c|c|c|c|c|}
\hline \multirow{2}{*}{$\begin{array}{c}\text { Point } \\
\text { number }\end{array}$} & \multirow{2}{*}{$\begin{array}{c}\text { Magnetic } \\
\text { induction } \\
\mathrm{B}(\mathrm{T})\end{array}$} & \multirow{2}{*}{$\begin{array}{c}\text { Vibrating } \\
\text { current } \\
\text { Iv (A) }\end{array}$} & \multicolumn{3}{|c|}{ Experimental results } & \multirow{2}{*}{$\begin{array}{c}\text { Other } \\
\text { conditions }\end{array}$} \\
\hline & & & $\begin{array}{c}\text { Conc. yield } \\
(\%)\end{array}$ & $\begin{array}{l}\mathrm{Fe} \text { in conc. } \\
(\% \mathrm{Fe} 2 \mathrm{O} 3)\end{array}$ & $\begin{array}{l}\text { Fe reduc- } \\
\text { tion }(\%)\end{array}$ & \\
\hline 1.00 & 0.80 & 2.50 & 71.61 & 0.08 & 68.40 & \multirow{6}{*}{$\begin{array}{c}\text { gas velocity } \\
2.2 \mathrm{~m} / \mathrm{s} \\
\text { filling facto } \\
11.5 \% \\
\text { feed mass: } \\
7 \mathrm{~g} \\
\text { feed time: } \\
4 \mathrm{~min}\end{array}$} \\
\hline 2.00 & 0.80 & 3.50 & 78.74 & 0.89 & 67.29 & \\
\hline 3.00 & 1.00 & 2.50 & 79.70 & 0.90 & 67.07 & \\
\hline 4.00 & 1.00 & 3.50 & 83.30 & 0.89 & 66.93 & \\
\hline 5.00 & 1.50 & 2.50 & 82.66 & 0.88 & 67.42 & \\
\hline 6.00 & 1.50 & 3.50 & 84.43 & 0.86 & 67.29 & \\
\hline
\end{tabular}

Table II Experimental results with sample no. 1, under composite conditions.

\begin{tabular}{||c|c|c|c|c|}
\hline Number & Product & Yield (\%) & Fe grade (\%) & Fe recovery (\%) \\
\hline \multirow{3}{*}{1.00} & Concentrate & 86.50 & 0.82 & 32.07 \\
\cline { 2 - 5 } & Tailings & 13.50 & 11.07 & 67.93 \\
\cline { 2 - 5 } & Feed & 100.00 & 2.20 & 100.00 \\
\hline \multirow{3}{*}{2.00} & Concentrate & 85.75 & 0.84 & 32.41 \\
\cline { 2 - 5 } & Tailings & 14.25 & 10.53 & 67.59 \\
\cline { 2 - 5 } & Feed & 100.00 & 2.22 & 100.00 \\
\hline
\end{tabular}

Table II shows good stability and high iron reduction in the experiments. The $\mathrm{Fe}_{2} \mathrm{O}_{3}$ content in sample no. 1 is reduced from $2.20 \%$ to $0.82 \%$ and the iron is removed with efficiency of $67.93 \%$ and with the yield of concentrate of $86.5 \%$. 


\section{Sample no 1 of Hard Kaolin}

In order to explore suitability of dry HGMS for removing iron from hard kaolin, another sample was investigated, The iron content in sample no .2 of hard kaolin was approximately $0.60 \%$. The optimum conditions were found to be the same as those obtained with sample no. 1, namely: magnetic induction: $1.0 \mathrm{~T}$, gas velocity $2.2 \mathrm{~m} / \mathrm{s}$, filling factor of the matrix: $11.5 \%$, vibrating current: $3.5 \mathrm{~A}$, feed: $7 \mathrm{~g}$, feed time: 4 minutes. The results are summarised in Table III.

Table III The experimental results of dry HGMS with no. 2 sample

\begin{tabular}{|c|c|c|c|}
\hline Product & Yield (\%) & Fe grade (\% Fe2O3) & Fe Recovery (\%) \\
\hline Concentrate & 83.15 & 0.48 & 65.33 \\
\hline Tailings & 16.85 & 1.19 & 34.67 \\
\hline Feed & 100.00 & 0.60 & 100.00 \\
\hline
\end{tabular}

Table III shows that dry HGMS is also efficient for hard kaolin containing lower concentration of iron. Concentration of $\mathrm{Fe}_{2} \mathrm{O}_{3}$ was reduced from $0.60 \%$ to $0.48 \%$ and the efficiency of $34.67 \%$ and with the yield concentrate of $83.15 \%$. The efficiency is, however, lower than with sample no. 1.

\section{CONCLUSIONS}

Dry high-gradient magnetic separation with matrix vibration was found to be effective in removing iron from hard kaolin powder which was dispersed by gas expansion. If this technology is proved on industrial scale it can be widely used in mining industry. The capital and running costs of dry HGMS are lower compared to the wet process. 


\section{REFERENCES}

[1] Yu Kangchun: Study of the removal of iron from kaolin by dry vibrating HGMS. Master Thesis, Central-South University of Technology, Changsha, China, 1990, (in Chinese)

[2] E.C. Hise et al.: Separation of dry crushed coals by HGMS. Report No. ORNL-4471 (1979)

[3] J. Iannicelli: New development in magnetic separation. IEEE Trans. Magn. 12 (1976), 436

[4] T. Oda et al.: Pulverised coal beneficiation by dry HGMS process. IEEE Trans.Magn. 19 (1983), 2121

[5] Zhang Jingming et al:: A study of removal of iron from coal ash by dry HGMS. Nonferrous MetaLS (Separation part) No. 12 (1989), 12 (in Chinese)

Keywords: kaolin, high-gradient magnetic separation, dry separation, matrix vibration

${ }^{\star}$ This paper was presented at the 4th International Conference "Theoretical and Technological Problems of the Physical Processing of Raw Materials" held in Kosice, Slovakia in October 1994. This adapted version is published with permission of the Institute of Geotechnics, Slovak Academy of Sciences, Kosice. 